\title{
O TRIDENTE DE NETUNO \\ Considerações sobre a bioquímica da origem da vida
}

WILLIAN SILVESTRE BENDAZZOLI

Farmacêutico-Bioquímico; Mestre em Bromatologia pela Faculdade de Ciências Farmacêuticas da USP; Professor e Coordenador do curso de Farmácia e Bioquímica da UNINOVE

\section{RESUMO}

A origem da vida é uma questão científico-filosófica polêmica que tem sido discutida ao longo de séculos. A teoria da Geração Espontânea, segundo a qual organismos brotavam espontaneamente de diversos materiais na natureza, permeou a ciência desde a época dos filósofos pré-socráticos até o fim do século XIX, quando foi derrubada por Louis Pasteur. O conhecimento atual sobre a bioquímica celular nos proporciona a visão da célula como um sistema altamente organizado e complexo. Os estudos modernos a respeito da origem da vida procuram reproduzir processos químicos que ocorreram em nosso planeta no período em que, acredita-se, a vida se tenha iniciado, objetivando formular hipóteses plausíveis para explicar como ela se iniciou. Explicações têm sido propostas para explicar parte da questão: a síntese de aminoácidos a partir de substâncias simples foi comprovada experimentalmente; reações de formação de carboidratos e nucleotídeos têm sido elucidadas; a origem das complexas macromoléculas biológicas talvez decorra de átomos de metais positivamente carregados que podem ter atraído monômeros que se polimerizaram; tioésteres têm sido propostos como possíveis precursores dos atuais metabólitos celulares. Atualmente, aceita-se a proposição do RNA como molécula informativa e catalítica implicada nos primeiros processos de origem da vida.

Palavras-chave: origem da vida; geração espontânea; Oparin; síntese pré-biótica; mundo do RNA; vida primitiva.

\section{ABSTRACT}

The origin of life is a polemical scientific-philosophic question that has been debated for ages. The theory of Spontaneous Generation, which declared that organisms sprouted spontaneously from various nature materials, permeated science since the Pre-Socratic philosophers' age until the end of the $19^{\text {th }}$ century, when it was declined by Louis Pasteur, who showed that life can not be originated from lifeless matter. The modern knowledge concerning cellular biochemistry teaches us that a cell is a highly complex and organized system. The current studies concerning the origin of life search to reproduce the chemical processes occurred in our planet by the supposed age in which life could has begun. Some explanations have been proposed to explain part of the question - the synthesis of aminoacids by single substances was carried out by Stanley Miller, during the mid 20th century. Reactions of carbohydrates, nucleotides and complex macromolecules formation have been currently investigated. The origin of the complex biological macromolecules is maybe originated from atoms of positively charged metals that can attract polymerized monomers. Thioesters have been considered as possible precursors of the current cellular methabolits. Presently it has been accepted the proposition of RNA as an informative and catalytic substance implicated in the earliest origin of life processes.

Key words: origin of life; spontaneous generation; Oparin; pre-biotic synthesis; RNA world; primitive life. 
$\mathrm{N}_{\mathrm{e}}^{\mathrm{a}}$ ascido em Florença, em 06 de março de 1475, e popularmente chamado Michelângelo, o jovem Miguel Ângelo Buonarroti, aos 30 anos, tornou-se conhecido como um dos maiores mestres da escultura em sua época. $\mathrm{Na}$ sua obstinação em esculpir posturas e movimentos humanos, Michelângelo estudou, com profundidade, a anatomia humana, dissecando cadáveres e desenhando com modelos. Mas em uma contingência histórica, sua genialidade legou ao mundo uma das mais belas obras: em 1508, o jovem artista, que se proclamava antes um escultor do que um pintor, foi convencido por autoridades florentinas a aceitar a encomenda feita pelo Papa Júlio II para a decoração da abóbada da capela Sistina, no Vaticano. É difícil não se impressionar com a grandiosidade da obra que resultou do trabalho de Michelângelo, um gigantesco afresco que representa episódios e personagens bíblicos. Não menos difícil nos é imaginar como ele realizou sua obra; além de idealizá-la com toda sua riqueza de detalhes, pintou-a sozinho, em uma posição pouco natural - deitado em andaimes e olhando para cima. A imagem central da pintura, A Criação de Adão, representa o ato da criação do homem por Deus. A figura de um Pai Criador, embalado por anjos e trazendo Adão à vida pelo toque de seu dedo, é sem dúvida uma das mais conhecidas e lembradas de sua arte. Assim como imortalizou Michelângelo em nossa história por sua genialidade, também serviu para moldar, no imaginário popular, $\mathrm{o}$ surgimento do homem por um Deus Pai criador afinal, como na poética de Maiakovski, a arte não é um espelho para refletir o mundo, mas um martelo para forjá-lo.

Embora a origem da vida seja uma questão com bases científicas e filosóficas, a idéia de uma origem como obra da criação divina transcende os tempos. Entre os filósofos, entretanto, amalgamouse conceito da Geração Espontânea. Os antigos filósofos gregos acreditavam que a vida fosse inerente à matéria, que pequenos animais ou mesmo vegetais poderiam espontaneamente brotar da terra, do ar ou da matéria orgânica se as condições fossem adequadas. A idéia atravessou a Idade Média e o Renascimento e ganhou força, nos séculos seguintes, com experimentos que ajudaram a consolidá-la. No século XVII, o médico e químico Jean-Baptist Van Helmont (DEBRÉ, 1995) acreditava que se pudesse fazer nascerem ratos espontaneamente, banhando-se grãos de trigo com o líquido extraído de uma camisa suja. De fato, a limitação tecnológica para a exploração da vida deu fôlego, por muito tempo, à teoria da Geração Espontânea, que alcançou seu auge e sucessiva queda, na segunda metade do século XIX. O pensamento científico e filosófico dos partidários da Geração Espontânea dessa época pode ser resumido pelas palavras de Archimède Pouchet (apud DEBRÉ, 1995), naturalista e médico, e diretor do Muséum d'Histoire Naturelle, de Rouen, na França: "A Geração Espontânea é a produção de um ser orgânico novo, desprovido de genitores e cujos elementos primordiais foram todos tirados da matéria ambiente". Pouchet era um fervoroso defensor de suas idéias e foi o mais tenaz inimigo de Louis Pasteur nessa questão. Em Paris, Pasteur provou, por meio de uma série de experimentos bem sucedidos, que microorganismos só podiam nascer de outros preexistentes - ou com suas palavras: "a vida é o germe, e o germe é vida" (apud DEBRÉ, 1995). Depois de Pasteur, a ciência não mais daria abrigo às proposições de surgimento espontâneo da vida - ainda que, em 1883, Carlo Collodi fizesse brotar Pinóchio de uma acha de madeira para o contentamento do velho e solitário marceneiro Gepeto.

Mas, ao nos debruçarmos hoje sobre a questão da origem da vida, o que podemos de fato concluir com base na ciência estabelecida? Mesmo com recursos tecnológicos para desenvolver pesquisas que aprofundem nosso conhecimento sobre a questão, uma pergunta ainda não está respondida: como surgiu a primeira forma de vida no planeta, uma vez que não teve genitores? Notadamente, nosso conhecimento sobre o assunto serviu de modo adicional para fragmentar a questão em múltiplas interrogações: considerando que uma célula vive, 
devido à perfeita organização estrutural e funcional de seus componentes, podemos considerar cada um deles como vivos? O que podemos então afirmar sobre os pequenos grupos funcionais orgânicos que compõem suas macromoléculas? Se suas propriedades químicas - ligações fortes e atrações químicas fracas - são responsáveis pela estruturação perfeita das grandes moléculas biológicas, então a vida, que depende de suas pequenas e grandes contribuições, também se estende a seu nível de grandeza? Portanto, em que nível da organização molecular começa a vida?

Seguramente, as respostas a essas questões extrapolam o domínio da ciência e caminham pela filosofia. Nossas dificuldades serão ainda maiores, levando-se em conta o fator tempo. Pouco sabemos sobre a química da vida primitiva bilhões de anos atrás, quando supomos que se originou. Considerando que sistemas químicos evoluem e se modificam, podemos somente traçar hipóteses plausíveis a respeito da química da vida primitiva, com base na observação da química da vida atual e nos registros fósseis e geológicos que, muitas vezes, são incompletos. Assim, é possível definir, minimamente, a vida como um sistema químico em meio aquoso que é capaz de evoluir transmitindo sua informação molecular. É razoável supor que esses sistemas evoluíram até atingir o complexo padrão da vida atual - e, procurando estabelecer os mecanismos pelos quais seus componentes devem ter sido originados, podemos estar mais perto de saber como a própria vida surgiu no planeta.

Uma célula, a menor unidade funcional da maioria dos seres vivos - e modelo do padrão da vida atual - é composta de uma miríade de moléculas orgânicas, pequenas ou grandes, algumas simples e outras extremamente complexas. Proteínas, ácidos nucléicos, carboidratos e lipídeos são os principais representantes dessas complexas estruturas biológicas, além de diversas substâncias menores, em geral nitrogenadas, responsáveis pela sinalização e comunicação celular. O nitrogênio desempenha importante função na construção de moléculas biológicas - em parte devido à possibilidade de formação de estereoisômeros, tornando ainda mais específica a relação entre suas estruturas e a função biológica. $\mathrm{O}$ fenômeno vida em uma célula é mantido pelo perfeito ordenamento das atividades deste conjunto de moléculas, principalmente das proteínas, cuja complexidade estrutural é responsável pelo desempenho de funções estritamente específicas - são elas as responsáveis pelo metabolismo celular, exercendo funções dinâmicas no sistema. Os ácidos nucléicos são os depositários da informação molecular a ser transmitida - somente mais recentemente as funções catalíticas do RNA foram explicitadas. O sistema químico é adequadamente isolado do meio externo por uma membrana lipídica. De uma célula, em geral jovem e indiferenciada, é possível originar-se outra, e o fenômeno vida é transmitido, desde que na nova célula existam as mesmas moléculas especializadas em suas funções, e que a façam funcionar. Uma célula é, portanto, a soma de suas partes, trabalhando em perfeita sincronia, e a vida emerge de sua organização em níveis ainda não totalmente compreendidos. Não obstante, se considerarmos - à exceção dos vírus - as células como as menores unidades do que entendemos como vivo, para compreender sua origem, devemos antes descobrir como podem ter surgido suas principais estruturas: as macromoléculas.

Todas as formas de vida conhecidas são formadas por carbono, hidrogênio, oxigênio, nitrogênio, enxofre e fósforo, e outros átomos em menor quantidade. Grandes moléculas biológicas são formadas pela combinação desses átomos sob diversas formas, notadamente em arranjos simples de grupos funcionais orgânicos que se repetem em suas estruturas. Pontes dissulfeto estabilizam as complexas estruturas protéicas. Carboxilas, aminas, álcoois e sulfidrilas contribuem para as elementares atrações entre hidrogênio e átomos eletronegativos, como nitrogênio e oxigênio, que unem ácidos nucléicos e, em conjunto com interações entre grupos hidrofóbicos, modelam as proteínas em suas 
gigantescas estruturas tridimensionais. A construção de macromoléculas, contudo, é resultante da polimerização de açúcares, aminoácidos e bases nitrogenadas ou seus precursores. Devemos buscar, portanto, na origem destas pequenas moléculas biológicas - presentes na Terra e até no espaço - o surgimento da vida.

Tal questão, entretanto, não é um problema simples. Hoje, graças ao grande desenvolvimento da química orgânica, conhecemos e dominamos inúmeras rotas sintéticas que, adequadamente controladas, podem levar à formação de moléculas biológicas a partir de substâncias relativamente simples. Fora destas condições, porém, - considerando a premissa básica de que a formação espontânea de moléculas orgânicas complexas é um evento termodinamicamente desfavorável - sua formação parece, em alguns casos, algo extremamente improvável. No entanto, esse evento ocorreu no passado em nosso planeta, e podemos procurar as pistas que nos levem à formulação de hipóteses para a origem de pequenos carboidratos e de moléculas nitrogenadas, como aminoácidos e as bases dos ácidos nucléicos.

A Terra foi formada há 4,6 bilhões de anos e o registro fóssil nos indica que as primeiras formas de microorganismos estavam presentes no planeta já há 3,6 bilhões de anos - muito cedo, portanto (SCHOPF, 1999). A formação de moléculas pré-bióticas, conseqüentemente, ocorreu antes dessa época. Devemos inicialmente identificar, no cenário da Terra de bilhões de anos atrás, fontes de carbono e de energia responsáveis pelas reações biossintéticas.

Sabemos que durante o período Arqueano - os primeiros 2,5 bilhões de anos do planeta - o esfriamento gradual da crosta terrestre e a pressão atmosférica adequada permitiram a condensação do vapor de água e sua precipitação sob a forma de chuvas. Junto com a água proveniente de cometas que bombardearam intensamente o planeta neste período, as chuvas formaram toda a massa de água líquida que cobre a maior parte da superfície da Terra (SALGADO-LABOURIAU,
1994). Nesse cenário, descargas elétricas liberadas pela colisão de nuvens eletricamente carregadas podem ter contribuído como uma poderosa fonte de energia para ativar reações biossintéticas entre moléculas de gases na atmosfera ou na água. Ainda na atmosfera, a radiação solar ultravioleta, altamente energética, também pode ter sido responsável pela formação de moléculas. O ozônio, que barra parte dos raios ultravioleta que atingem a Terra, só surgiria mais tarde, derivado do oxigênio gerado pelos organismos fotossintetizantes. Diversas substâncias orgânicas têm sido identificadas em nuvens interestelares e, provavelmente, resultam de processos fotoquímicos de biossíntese, nos quais a colisão de raios cósmicos com átomos simples, como hidrogênio e hélio talvez tenha gerado moléculas maiores. Substâncias orgânicas simples, entre elas formaldeído $\left(\mathrm{H}_{2} \mathrm{CO}\right)$ e ácido cianídrico $(\mathrm{HCN})$, têm sido encontradas em cometas, e vários aminoácidos já foram identificados em meteoritos que chegaram à Terra. No planeta ainda jovem, o vulcanismo era muito mais intenso e, mais do que hoje, grande quantidade de gases aprisionados abaixo da crosta foram eliminados na atmosfera. Com o esfriamento gradual da Terra, o processo diminuiu, mas continua nos vulcões e chaminés hidrotermais submarinas, onde o calor pode ter sido uma razoável fonte de energia para a biossíntese de substâncias orgânicas a partir de moléculas dos gases liberados (BRACK, 1998).

Após a formação do planeta, as principais fontes de carbono para a formação de moléculas pré-bióticas - além das substâncias orgânicas provenientes de cometas e meteoros - foram os gases atmosféricos. Entretanto, a composição exata da atmosfera primitiva do planeta não é conhecida - as rochas mais antigas identificadas, localizadas na Groenlândia, datam de 3,8 bilhões de anos e preservam muito pouca informação sobre a composição da atmosfera dessa época. Sabemos, por meio da datação de depósitos de rochas calcáreas submarinas que, nesse período, grande quantidade do $\mathrm{CO}_{2}$ atmosférico foi 
removida pelas chuvas para os oceanos formando carbonatos insolúveis com o cálcio da crosta. A quantidade de oxigênio molecular $\left(\mathrm{O}_{2}\right)$ possivelmente era mínima, decorrente apenas da fotólise da água pela radiação solar ultravioleta, resultando também em hidrogênio molecular $\left(\mathrm{H}_{2}\right)$, mas este, por ser muito leve, não é retido pela gravidade e escapa para o espaço (SALGADOLABOURIAU, 1994; BRACK, 1998).

\section{A ATMOSFERA TERRESTRE E AS MOLÉCULAS PRÉ-BIÓTICAS}

Em um pioneiro estudo sobre a química prébiótica da origem da vida de 1938, o bioquímico russo Aleksandr Ivanovich Oparin (apud SCHOPF, 1983) postulou que moléculas pré-bióticas foram formadas em uma atmosfera terrestre redutora. Observou ainda que em cometas e meteoritos e em alguns planetas gigantes gasosos, como Júpiter e Saturno, o carbono ocorre na forma reduzida, combinado com nitrogênio sob a forma de ácido cianídrico (HCN). Assim, propôs que a atmosfera primitiva era composta de metano $\left(\mathrm{CH}_{4}\right)$, amônia $\left(\mathrm{NH}_{3}\right)$, hidrogênio molecular $\left(\mathrm{H}_{2}\right) \mathrm{e}$ vapor de água $\left(\mathrm{H}_{2} \mathrm{O}\right)$, e que o oxigênio molecular $\left(\mathrm{O}_{2}\right)$ não estaria presente na atmosfera bilhões de anos atrás - antes do surgimento dos primeiros organismos -, pois é resultado da fotossíntese. Adicionalmente, observou que o oxigênio reage facilmente com substâncias orgânicas, oxidandoas, o que impediria o acúmulo das moléculas prébióticas que, por fim, resultariam na primeira forma de vida. Contrastando com a hipótese de Oparin, William Rubey (apud SCHOPF, 1983) estudou a composição de rochas terrestres e de emissões vulcânicas e, em 1955 postulou que a composição da atmosfera primitiva era basicamente de $\mathrm{CO}_{2}, \mathrm{~N}_{2}$ e $\mathrm{H}_{2} \mathrm{O}$. De acordo com Rubey, não havia evidências no registro geológico que pudessem apoiar a idéia de uma atmosfera com caráter redutor, baseada em $\mathrm{CH}_{4} \mathrm{e} \mathrm{NH}_{3}$, como defendia Oparin. Em 1962, H. D. Holland (SCHOPF, 1983) propôs um modelo conciliador, no qual a atmosfera inicialmente foi dominada por $\mathrm{CH}_{4}$, e gradualmente foi perdendo o caráter redutor devido ao aumento do $\mathrm{CO}_{2}$ atmosférico, expelido em grande quantidade pelos processos de vulcanismo.

Com base na proposição de Oparin, Stanley Miller provou, em 1953, que é possível a síntese de aminoácidos a partir de uma mistura de gases simulando uma atmosfera fortemente redutora. Ele utilizou uma mistura de vapor de água e de $\mathrm{CH}_{4}, \mathrm{NH}_{3}$ e $\mathrm{H}_{2}$, em um recipiente fechado contendo também água líquida. Submetendo-a a descargas elétricas semelhantes às atmosféricas, foram obtidos, sobre a água, uréia, ácidos graxos de cadeia curta e aminoácidos - muitos com grande rendimento e de importância biológica, como alanina, glicina e os ácidos aspártico e glutâmico. Miller verificou que os aminoácidos resultaram da reação no meio aquoso entre HCN e aldeídos formados pelas descargas elétricas. O carbono na forma reduzida $\left(\mathrm{CH}_{4}\right)$, em contrapartida ao $\mathrm{CO}_{2}$ e CO, mostrou-se mais eficaz na produção de aminoácidos. A formação de ácidos orgânicos aminados é, portanto, um processo aparentemente comum na natureza, desde que as condições necessárias prevaleçam seja na Terra ou no meio interestelar (MILLER, 1953; MILLER, 1955; BRACK, 1998). Sua formação pode ocorrer por polimerização espontânea de HCN, como provou John Oró em 1961. HCN, entretanto, também pode ter sido importante na formação de bases nitrogenadas, sobretudo de adenina. Oró provou que a polimerização de tetrâmeros de HCN é uma reação que ocorre espontaneamente e é acelerada pela presença de formaldeído - ambos compostos que talvez sejam formados nas condições do experimento de Stanley Miller (ORÓ, 1961; BRACK, 1998):

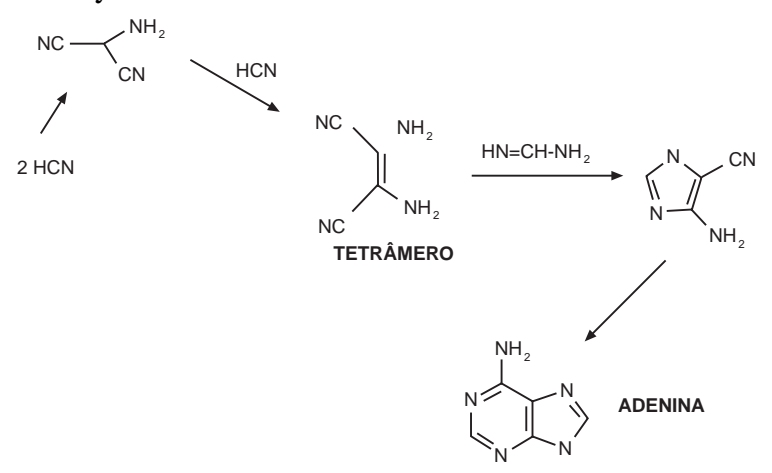


Variações no processo de síntese podem levar à formação de outras purinas, como guanina e xantina. A síntese de pirimidinas por polimerização de HCN, entretanto, é pouco significativa. Porém, se a formação de aminoácidos e bases nitrogenadas é aparentemente simples, a síntese de açúcares - também constituintes da estrutura de ácidos nucléicos - é um processo muito mais complexo. Monossacarídeos podem formar-se espontaneamente por polimerização de formaldeído $\left(\mathrm{H}_{2} \mathrm{CO}\right)$. A formação de ribose $\left(\mathrm{C}_{5} \mathrm{H}_{10} \mathrm{O}_{5}\right)$, por exemplo, - que é o monossacarídeo presente em nucleotídeos - envolve a polimerização de cinco moléculas de $\mathrm{H}_{2} \mathrm{CO}$ (GABEL; PONNAMPERUMA, 1967):

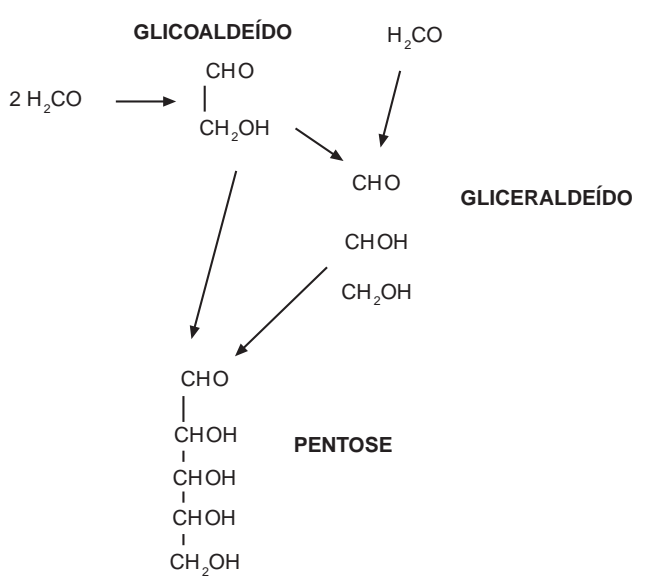

No entanto, $\mathrm{H}_{2} \mathrm{CO}$ somente se forma em quantidades significativas em atmosferas fracamente redutoras, com predominância de $\mathrm{CO}_{2}$ e $\mathrm{N}_{2}$, por meio da redução do $\mathrm{CO}_{2}$ pelo hidrogênio molecular $\left(\mathrm{H}_{2}\right)$. Outro problema é a dificuldade de formação seletiva de ribose, de modo a prover quantidade significativa deste monossacarídeo para a formação de ácidos nucléicos. Normalmente, reações de formação de carboidratos levam a misturas complexas com dezenas de moléculas e isômeros resultantes (DECKER et al., 1982). Adicionalmente, a ribose é instável - sua meia-vida a $100^{\circ} \mathrm{C}$ e pH 7,0 é de 73 minutos, o que nos leva a crer que, apenas se fosse usada imediatamente após sua biossíntese, seria útil para a formação de nucleotídeos (LARRALDE et al., 1995). Substitutos estáveis para a ribose na formação pré-biótica de precusores de ácidos nucléicos têm sido procurados. Os resultados, porém, ainda não são promissores.

\section{AS MACROMOLÉCULAS E O INÍCIO DA VIDA}

Moléculas como proteínas ou ácidos nucléicos surgiram muito cedo no planeta, possivelmente em um período inferior a 900 milhões de anos, já que os primeiros microorganismos datam de 3,6 bilhões de anos (GOULD, 1993). Não obstante, para explicar a formação destas macromoléculas, devemos inicialmente considerar que o problema da formação de pequenas moléculas pré-bióticas, como aminoácidos, açúcares simples e bases nitrogenadas - ou até mesmo nucleotídeos, possa ter sido resolvido, com maior ou menor dificuldade, há bilhões de anos. Conseqüentemente, podemos admitir, como plausível, que sua polimerização, levando à formação das macromoléculas funcionais, como proteínas, ou informativas, como ácidos nucléicos, talvez tenha ocorrido espontaneamente, ou com o auxílio de algum catalisador, caso o processo fosse termodinamicamente desfavorável. Embora nos pareça relativamente fácil explicar o aumento da complexidade molecular unicamente em termos químicos - e algumas hipóteses existentes, de fato, podem prover soluções confortáveis -, não é exagero dizer que muito mais difícil é explicar a origem do elevado conteúdo de informação que essas moléculas carregam.

Como não é possível dissociar maior complexidade estrutural do aumento da incorporação de informação, e tendo muito poucas evidências experimentais, somos levados a caminhar pelo cativante e temerário terreno das hipóteses, para tentar explicar o surgimento de macromoléculas biológicas. Não subestimemos, entretanto, os prodígios do intelecto na busca de soluções. Dante temeu entrar pelos domínios do inferno desconhecido; no entanto, em sua jornada, sabiamente foi conduzido pelo determinado Virgílio - "Qui si convien lasciare ogne sospetto; ogne viltà convien che qui sai 
morta. Noi siam venuti al loco ov' i' t'ho detto che tu vedrai le genti dolorose c'hanno perduto il ben de l'inteletto".

Parece-nos, de fato, que a complexidade está associada à funcionalidade e à vida. Günter Wächtershäuser postulou, em 1992, que a origem da vida estaria na origem da funcionalidade, e que houve um precursor funcional comum aos atuais metabólitos celulares. O sulfeto de ferro (FeS) seria o precursor funcional comum de todos os agentes bioquímicos redutores desde a origem da vida e, portanto, esta se teria originado deste mineral. De acordo com Wächtershäuser, a oxidação de $\mathrm{FeS}$, formando pirita $\left(\mathrm{FeS}_{2}\right)$, proveria elétrons para desencadear os processos redutores de formação de macromoléculas:

$\mathrm{FeS}+\mathrm{H}_{2} \mathrm{~S} \rightarrow \mathrm{FeS}_{2}+2 \mathrm{e}^{-}+2 \mathrm{H}^{+}$

Wächtershäuser observou que, da mesma forma que a célula, por ser um compartimento isolado e que mantém próximos os metabólitos que interagem, o precursor dessa organização celular teria sido alguma substância que provesse uma superfície reacional na qual outros metabólitos que fossem ligados poderiam reagir mais facilmente, devido à sua proximidade. Diante disso, postulou que esta substância teria sido o $\mathrm{FeS}_{2}$ que, por apresentar sua superfície carregada positivamente, comporta-se como um ligante policatiônico para metabólitos aniônicos. Assim, aplicou seu raciocínio a carboxilas de aminoácidos, nucleotídeos e açúcares fosforilados como potenciais metabólitos aniônicos que possam polimerizar-se, se ligados à superfície reacional do $\mathrm{FeS}_{2}$. Adicionalmente, o $\mathrm{FeS}$, em conjunto com $\mathrm{H}_{2} \mathrm{~S}$, poderia estar implicado na formação de tioésteres. A redução de $\mathrm{CO}_{2}$ a acetato e, sucessivamente, a tioacetato seria importante na formação dos primeiros metabólitos celulares:

$$
\begin{aligned}
& \mathrm{CO}_{2}+\mathrm{FeS} / \mathrm{H}_{2} \mathrm{~S} \rightarrow \mathrm{CH}_{3}-\mathrm{SH}+\mathrm{FeS}_{2} . \\
& \mathrm{CH}_{3}-\mathrm{SH}+\mathrm{CO} \rightarrow \mathrm{CH}_{3}-\mathrm{CO}-\mathrm{SH}
\end{aligned}
$$

1 "Livra-te desse medo circunspecto; aqui toda tibiez esteja morta; que chegando ora estamos ao conspecto das tristes gentes das quais já te disse que têm perdido o bem do intelecto." (tradução nossa).
Tioésteres desempenham funções importantes no metabolismo atual. A acetil-coenzima A - um tioacetato ligado covalentemente a uma coenzima composta de ácido pantotênico e adenosina difosfatada - é um dos metabólitos centrais nos processos catabólicos e anabólicos do metabolismo aeróbico. Grupos sulfidrilas também participam ativamente dos sítios ativos de muitas enzimas. $\mathrm{O}$ modelo de Wächtershäuser, portanto, prevê que as reações do metabolismo primitivo ocorreram com a imobilização de seus reagentes. De fato, é importante considerarmos que as substâncias formadoras das primeiras macromoléculas biológicas precisariam estar próximas, possivelmente confinadas em um microambiente favorável e estável. Um meio reacional bidimensional líquido, com reagentes imobilizados que pudessem reagir, ou um meio tridimensional, líquido e concentrado, e rico em substâncias orgânicas - em que as moléculas tivessem mobilidade - seriam opções adequadas.

Atualmente, tem sido aceito que, entre as macromoléculas biológicas, o RNA precedeu as proteínas e o DNA no cenário terreno, na conceituação de um chamado 'Mundo do RNA', no qual este ácido nucléico apresentaria atividades catalíticas responsáveis pelo metabolismo primitivo. Verdadeiramente, algumas moléculas de RNA podem comportar-se como enzimas - são as chamadas ribozimas. Segundo Alan Schwartz (BRACK, 1998), o 'Mundo do RNA' ter-se-ia iniciado com polinucleotídeos, provavelmente formados por polimerização de nucleotídeos dispersos em um meio reacional confinado. Estas pequenas unidades formadas, poderiam então ter catalisado a síntese de cópias delas próprias levando, por fim, à síntese de moléculas maiores o próprio RNA. A replicação dessas moléculas informativas poderia incorporar erros no processo, formando moléculas mutadas, em alguns casos mais estáveis do que o modelo original, e aumentando a variedade de polinucleotídeos, em um processo de evolução Darwiniana. Finalmente, todo o processo culminaria no metabolismo como o conhecemos hoje (BRACK, 1998). 
No entanto, a idéia de que o desenvolvimento das estruturas celulares e do metabolismo atual tenha ocorrido a partir de polinucleotídeos ou RNA também tem sido preterida em relação à idéia de uma origem enzimática/protéica. De acordo com Christian De Duve (1997), as ribozimas não conseguem responder por toda a faixa de atividades catalíticas do metabolismo atual nem poderiam ter sido responsáveis pelas reações biossintéticas que levaram à sua formação. Portanto, não teriam levado ao desenvolvimento da vida tal qual a conhecemos atualmente. De Duve tem defendido a idéia de que o 'Mundo do RNA' seria responsável por um protometabolismo, no qual teriam sido geradas as condições para o desenvolvimento de proteínas e enzimas por um mecanismo RNAdependente, e estas, finalmente, viriam a responder pelo desenvolvimento do metabolismo das estruturas celulares, uma vez que podem cobrir uma faixa mais ampla de atividade catalítica (DE DUVE, 1997). De fato, é inimaginável o número de estruturas protéicas possíveis baseadas na combinação dos vinte aminoácidos protéicos, em quantidade e posição.

A idéia, portanto, de o RNA ter sido a primeira molécula biológica complexa surgida no planeta parece bem aceita. Porém, explicar sua origem bem como de nucleotídeos e de como se deu sua polimerização - permanece ainda uma grande dificuldade. Talvez a alternativa mais extrema para explicar a origem de macromoléculas esteja relacionada às idéias de Cairns-Smith (BRACK, 1998). Sua teoria propõe que alguns tipos de cristais de minerais da argila serviram de depósito de informação molecular em determinadas conformações específicas. Os cristais teriam proliferado e essas conformações replicadas. Em determinado momento, notavelmente, maquinário fotoquímico teria sido desenvolvido, gerando moléculas orgânicas que catalisariam a formação de mais cristais com conformações favoráveis, e os nucleotídeos formados por reações orgânicas ter-se-iam polimerizado e servido para alinhar aminoácidos em pequenas cadeias protéicas. Finalmente, a substituição de minerais por moléculas orgânicas teria então ocorrido, e a argila dispensada (BRACK, 1998). Não deixa de ser notável que, prosaicamente, sua argumentação tangencie a idéia criacionista baseada no mesmo princípio - "Então o Senhor Deus formou o homem do pó da terra e soprou em suas narinas o fôlego da vida, e o homem se tornou um ser vivente". ${ }^{2}$

Seja como for, por mais improvável que pareça, essas complexas moléculas informativas e funcionais foram formadas a partir de substâncias simples, evoluíram e levaram à formação das primeiras células - os primitivos microorganismos, que reinaram absolutos na Terra até o surgimento dos organismos pluricelulares há 600 milhões de anos (GOULD, 1993). Para a vida, que se iniciou há 3,6 bilhões de anos, além de pequenas moléculas orgânicas e de energia, também foi fundamental a presença de um meio reacional líquido, em que puderam ocorrer reações químicas pré-bióticas. Um meio feito de água líquida. Devemos nossa existência à água, nosso primeiro berço. Mas onde a vida teria começado - na primeira célula, no RNA ou nas proteínas, nas pequenas moléculas orgânicas que os formaram, ou mesmo no barro de CairnsSmith - é uma questão à qual, creio, seja difícil responder com total isenção de influências filosófico-culturais. Hoje, porém, temos a recompensa de conhecermos cada vez melhor quais foram as condições necessárias para o surgimento da vida.

Netuno, Senhor absoluto das águas, a quem os romanos consagravam o mês de fevereiro, com sua longa barba percorria os oceanos em sua carruagem puxada por cavalos marinhos, e usava seu tridente para agitar as águas e criar tempestades. Tempestades de raios e trovões, energia e síntese pré-biótica. Assim como o pincel de Michelângelo trouxe à vida um Adão moldado por Deus, numa paródia científica, seu tridente trouxe a vida às águas.

2 Gênesis - 2,7 


\section{REFERÊNCIAS BIBLIOGRÁFICAS}

BRACK, A. The Molecular Origins of Life. Cambridge: Cambridge University Press, 1998. 418 p.

DE DUVE, C. Poeira Vital. Rio de Janeiro: Campus, 1997. $472 \mathrm{p}$.

DEBRÉ, P. Pasteur. São Paulo: Página Aberta, 1995. $576 \mathrm{p}$.

DECKER, P.; SCHWEER, H.; POHLMANN, R. Identification of formose sugars, presumable prebiotic metabolits, using capillary gas chromatography / gas chromatography-mass spectrometry of n-butoxime trifluoroacetates on ov-225. J. Chromatography, v. 225, p. 281-291, 1982.

GABEL, N. W.; PONNAMPERUMA, C. Model for origin of monossacharides. Nature, v. 216, p. 453455, 1967.

GOULD, S. J. The Book of Life. New York: W. W. Norton; Company, 1993. 256 p.

LARRALDE, R.; ROBERTSON, M. P.; MILLER, S. L. Rates of decomposition of ribose and other sugars: implications of chemical evolution. Proc. Natl. Acad. Sci. USA, v. 92, p. 8158-8160, 1995.

MILLER, S. L. Production of amino acids under possible primitive Earth conditions. Science, v. 117, p. 528-529, 1953.

Production of some organic compounds under possible primitive Earth conditions. J. Am. Chem.Soc., v. 77, p. 2351-2361, 1955.
ORÓ, J. Amino-acid synthesis from hydrogen cyanide under possible primitive Earth conditions. Nature, v. 190, p. 442-443, 1961.

SALGADO-LABOURIAU, M. L. História Ecológica da Terra. São Paulo: Edgard Blücher, 1994. 308 p.

SCHOPF, J. W. Earth's Earliest Biosphere - Its Origin and Evolution. New Jersey: Princeton University Press, 1983. 544 p.

. Cradle Of Life - The Discovery of Earth's Earliest Fossils. New Jersey: Princeton University Press, 1999. 368 p.

WÄCHTERSHÄUSER, G. Groundworks for an evolutionary biochemistry: the iron-sulphur world. Prog. Bioph. Mol. Biol., v. 58, p.85-201, 1992.

\section{BIBLIOGRAFIA SUGERIDA}

DELSEMME, A. Our Cosmic Origins. Cambridge: Cambridge University Press, 1998. 322 p.

EL-HANI, C. N.; Videira, A. A. P. O Que é Vida? - Para Entender a Biologia do Século XXI. Rio de Janeiro: Dumará, 2000. 312 p.

FRY, I. The Emergence of Life on Earth. New Jersey: Rutgers University Press, 2000. 330 p.

LEWIN, R. Complexity - Life at the Edge of Chaos. 2nd. ed. Chicago: The University of Chicago Press, 1999. 236 p. 


$$
\longrightarrow
$$

